\title{
Analisis Finansial dan Sensitivitas Usaha Kecil Menengah Dodol Coklat
}

\section{Financial Analysis and Sensitivity of Chocolate Dodol Home Industry}

\author{
Fibra Nurainy $^{1}$, Otik Nawansih ${ }^{1}$, dan Merry Monika Sitanggang ${ }^{2}$ \\ ${ }^{1)}$ Dosen Jurusan Teknologi Hasil Pertanian Fakultas Pertanian Universitas Lampung Jl. \\ Prof. Soemantri Brojonegoro No. 1 Bandar Lampung, Lampung 35145 \\ ${ }^{2)}$ Alumni Jurusan Teknologi Hasil Pertanian, Fakultas Pertanian, Universitas Lampung \\ Email : merymonica1204@gmail.com
}

\begin{abstract}
This research was purposed to determine financial aspects of chocolate dodol home industry. The result of investment feasibility are reasonable to continue (NPV $>0$, Net $B / C>1, I R R>22 \%$ discount rate and raw's material (cocoa beans) as many as $10 \%$ $50 \%$ and the fuel as many as 15\%-90 PP< 5 years of economical's age. The result of sensitivity variable cost increase likes \% still reasonable to continue (NPV>0, Net B/C $>1, I R R>22 \%$ discount rate and $P P<5$ years of economical's age).
\end{abstract}

Keywords: Chocolate dodol, Financial Analysis, Sensitivity.

Diterima: 12-12-2014 : disetujui 23-10-2015

\section{PENDAHULUAN}

Kakao merupakan salah satu komoditas ekspor yang dapat memberikan kontribusi untuk peningkatan devisa negara. Indonesia merupakan salah satu negara pemasok utama kakao dunia dengan persentase 13,6\% (BPS, 2011). Luas areal tanaman kakao pada tahun 2010 yaitu 48.343 ha dan pada tahun 2012 meningkat menjadi 51.064 ha (Direktorat Jenderal Perkebunan, 2012). Produksi kakao pada tahun 2012 yaitu 26.719 ton (BPS, 2012).

Proses pengolahan kakao di tingkat petani masih dapat dikatakan minim. Hal ini dikarenakan usaha pengolahan biji kakao masih berpegang dari segi kuantitas dan kecepatan dalam menghasilkan uang sehingga selama ini petani kakao menjualnya masih dalam bentuk biji. Permasalahan yang dihadapi petani adalah ketidakstabilan harga kakao, sehingga pada saat harga kakao turun, penghasilan petani menjadi menurun dan merugi. Salah satu bentuk pengolahan dari biji kakao di tingkat petani yaitu dodol coklat. Pembuatan dodol coklat mempunyai peluang untuk dikembangkan di tingkat petani karena tidak memerlukan peralatan yang harganya mahal, sehingga lebih terjangkau bagi para petani untuk mengusahakannya. Penelitian ini bertujuan untuk mengetahui analisis finansial dan sensitivitas Usaha Kecil Menengah (UKM) dodol coklat. 



\section{METODE}

Penelitian ini dilaksanakan pada bulan Februari sampai dengan April 2014. Analisis finansial dilakukan pada dodol coklat dengan perbandingan tepung ketan dan bubuk coklat 70 :30 hasil dari penelitian yang telah dilakukan. Analisis yang akan digunakan dalam penelitian ini adalah Break Evet Point, Payback Period (PP) (Sjahrial, 2008), Net Present Value (NPV) (Kadariah dan Gray, 1999), Internal Rate Return(IRR), Net B/C ratio dan analisis sensitivitas (Rizki, 2011) yang diananlis menggunakan program microsoft excell.

\section{HASIL DAN PEMBAHASAN}

\section{a. Asumsi}

1. Ananlisis Finansial dilakukan selama 5 tahun dengan perincian; tahun Ke-0 digunakan untuk survei dan persiapan tempat, sedangkan operasi dilakukan pada tahun ke-1 dengan kapasitas 65 $\%$, tahun ke-2 sebesar 70\%, tahun ke-3 75\% dan pada tahun ke-4 sampai ke-5 80\%.

2. Biaya pemeliharaan dan perbaikan modal tetap dengan kisaran $3 \%$ pertahun dari nilai investasi barang pada tahun ke-3 dan ke-5

3. Upah karyawan Rp $1.400 .000,00 /$ bulan, satu bulan $=25$ hari kerja

4. Kapasitas produksi adalah $120 \mathrm{pak} / \mathrm{hari} \mathrm{x} 25$ hari/bulan $=3000$ pack, 1 tahun=36000pack

5. Modal yang digunakan merupakan modal sendiri.

6. Besarnya biaya penyusutan dihitung dengan metode garis lurus yang disesuaikan dengan umur ekonomis masing-masing modal tetap.

7. Nilai sisa dari peralatan adalah $10 \%$ dari total biaya mesin dan peralatan.

8. Pajak Penghasilan (PPh) menurut Sk Peraturan Pemerintah Nomor 46 tahun 2013 tentang pajak penghasilan atas penghasilan dari usaha yakni wajib pajak kepada orang pribadi dan badan usaha yang menerima penghasilan dari usaha dengan peredaran bruto (omzet) yang tidak melebihi Rp. 4, 800. 000. 000, 00 (Empat Miliar Delapan Ratus Juta Rupiah) dalam 1 (satu) Tahun Pajak. Pajak yang terhutang dan harus dibayar adalah $1 \%$ dari jumlah peredaran bruto (Omzet).

\section{Biaya Investasi Usaha dan Penyusutan}

\begin{tabular}{|c|c|c|c|c|c|c|c|}
\hline Uraian & Jumlah & Satuan & $\begin{array}{c}\text { Harga } \\
\text { (Satuan) }\end{array}$ & Total (Rp) & $\begin{array}{c}\text { Umur } \\
\text { Ekonomis }\end{array}$ & $\begin{array}{c}\text { Nilai Sisa } \\
10 \%\end{array}$ & $\begin{array}{c}\text { Penyusutan } \\
\text { Pertahun } \\
(\mathrm{Rp})\end{array}$ \\
\hline \multicolumn{8}{|l|}{ A.Bangunan } \\
\hline Sewa Tempat & 1 & Tempat & 10.000 .000 & 10.000 .000 & & & \\
\hline \multicolumn{8}{|c|}{ B.Mesin dan Peralatan } \\
\hline wajan & 5 & unit & 200.000 & 1.000 .000 & 3 & 20.000 & 326.667 \\
\hline kompor gas & 5 & Unit & 200.000 & 1.000 .000 & 3 & 20.000 & 326.667 \\
\hline timbangan & 5 & Unit & 100.000 & 500.000 & 3 & 10.000 & 163.333 \\
\hline grinder & 5 & Unit & 200.000 & 1.000 .000 & 3 & 20.000 & 326.667 \\
\hline pengaduk kayu & 10 & Unit & 10.000 & 100.000 & 1 & 1.000 & 99.000 \\
\hline loyang & 100 & Unit & 3.000 & 300.000 & 2 & 300 & 149.850 \\
\hline baskom & 10 & Unit & 5.000 & 50.000 & 3 & 500 & 16.500 \\
\hline tabung gas $12 \mathrm{~kg}$ & 5 & Unit & 400.000 & 2.000 .000 & 4 & 40.000 & 490.000 \\
\hline sendok & 5 & lusin & 20.000 & 100.000 & 2 & 2.000 & 49.000 \\
\hline Total & & & & 16.050 .000 & & 113.800 & 1.947 .683 \\
\hline Total Investasi & & & & 26.050 .000 & & & \\
\hline
\end{tabular}


Jurnal Penelitian Pertanian Terapan

2. Biaya Tetap dan Tidak tetap

\begin{tabular}{|c|c|c|c|c|c|}
\hline Rincian Biaya & Tahun Ke-1 & Tahun Ke-2 & Tahun Ke -3 & Tahun Ke-4 & Tahun Ke-5 \\
\hline \multicolumn{6}{|l|}{ Biaya Tetap (Rp) } \\
\hline a. Perbaikan & & & 481.500 & & 481.500 \\
\hline $\begin{array}{l}\text { b. Biaya } \\
\text { Penyusutan }\end{array}$ & 1.947 .683 & 1.947 .683 & 1.947 .683 & 1.947 .683 & 1.947 .683 \\
\hline $\begin{array}{l}\text { c. Tenaga Kerja } \\
\text { Bulanan }\end{array}$ & 50.400 .000 & 50.400 .000 & 50.400 .000 & 50.400 .000 & 50.400 .000 \\
\hline d. Listrik & 1.200 .000 & 1.200 .000 & 1.200 .000 & 1.200 .000 & 1.200 .000 \\
\hline Total & 53.547 .683 & 53.547 .683 & 54.029 .183 & 53.547 .683 & 54.029 .183 \\
\hline \multicolumn{6}{|l|}{$\begin{array}{l}\text { Biaya Variabel } \\
\text { (Rp) }\end{array}$} \\
\hline a. Bubuk coklat & 27.000 .000 & 27.000 .000 & 27.000 .000 & 27.000 .000 & 27.000 .000 \\
\hline b.Tepung ketan & 37.800 .000 & 37.800 .000 & 37.800 .000 & 37.800 .000 & 37.800 .000 \\
\hline c.Gula pasir & 45.000 .000 & 45.000 .000 & 45.000 .000 & 45.000 .000 & 45.000 .000 \\
\hline d. Santan kelapa & 18.000 .000 & 18.000 .000 & 18.000 .000 & 18.000 .000 & 18.000 .000 \\
\hline e.Bahan Bakar & 7.200 .000 & 7.200 .000 & 7.200 .000 & 7.200 .000 & 7.200 .000 \\
\hline $\begin{array}{l}\text { f. Bahan } \\
\text { Pengemas }\end{array}$ & 22800000 & 22800000 & 22800000 & 22800000 & 22800000 \\
\hline g. Label & 5.000 .000 & 5.000 .000 & 5.000 .000 & 5.000 .000 & 5.000 .000 \\
\hline Total & 162.800 .000 & 162.800 .000 & 162.800 .000 & 162.800 .000 & 162.800 .000 \\
\hline Total Biaya & 216.347 .683 & 216.347 .683 & 216.829 .183 & 216.347 .683 & 216.829 .183 \\
\hline
\end{tabular}

b. Harga Pokok Penjualan (HPP)

HPP $=$ Total biaya pertahun Total produksi pertahun

$\mathrm{HPP}=218.397 .533=6.066 .59 / \mathrm{pack}$ 36000

Laba yang diinginkan $=(70 \% \mathrm{x}$ biaya operasional $)$

$$
\begin{aligned}
& =70 \% \times 218.397 .533 \\
& =152.878 .273
\end{aligned}
$$

Harga jual

$$
\begin{aligned}
& =\frac{\text { laba }+ \text { biaya operasional }}{\text { total produksi }} \\
& =\frac{152.878 .273+218.397 .533}{36000} \\
& =10.313 .216
\end{aligned}
$$

Berdasarkan perhitungan diatas. maka harga jual dodol coklat dibulatkan menjadi sebesar Rp 11.000.-

\section{c. Penerimaan Usaha}

Industri skala rumah tangga dodol coklat diproyeksikan untuk lima tahun kedepan. Kegiatan operasi diasumsikan pada tahun pertama yakni $65 \%$. pada tahun ke-2 yakni $70 \%$. pada tahun ke-3 yakni $75 \%$ dan pada tahun ke-3 dan ke-4 yakni $80 \%$.

Total penerimaan $=$ jumlah produksi dodol coklat per tahun $\mathrm{x}$ harga jual produk

$$
\begin{aligned}
& =36000 \text { pack } \times \text { Rp 11.000.- } \\
& =\operatorname{Rp~396.000.000.-~}
\end{aligned}
$$


Jurnal Penelitian Pertanian Terapan

Tabel 1. Penerimaan Usaha Dodol Coklat

\begin{tabular}{lllllll}
\hline \multirow{2}{*}{ No } & \multirow{2}{*}{ Nama UKM } & \multicolumn{5}{c}{ Penerimaan Pertahun (Rp) } \\
\cline { 3 - 6 } & & Tahun ke-1 & Tahun ke-2 & Tahun ke-3 & Tahun ke-4 & Tahun ke-5 \\
\hline \multirow{2}{*}{1} & UKM X & 257.400 .000 & 277.200 .000 & 297.000 .000 & 316.800 .000 & 316.800 .000 \\
\hline
\end{tabular}

Berdasarkan data tersebut tingkat penerimaan usaha dodol coklat pada tahun ke-1 hingga tahun ke-5 mengalami kenaikan. Presentasi penerimaan keuntungan usaha dodol coklat tersebut diasumsikan bahwa nilai keuntungan tersebut pada tahun pertama yakni faktor perkalian $65 \%$ hingga tahun ke-5 dengan faktor perkalian $80 \%$.

\section{d. Analisis Titik Impas}

Berikut ini adalah tebel nilai titik impas berdasarkan BEP Unit dan BEP Harga UKM dodol coklat.

BEP unit $=$ (Biaya tetap)

(Harga per unit-Biaya variabel/unit)

BEP harga $=$ (Biaya tetap) (harga jual per unit-biaya variabel per unit)/harga per unit)

Tabel 2. Analisis titik impas

\begin{tabular}{cccc}
\hline \multirow{2}{*}{ No } & \multirow{2}{*}{ Nama UKM } & \multicolumn{2}{c}{ Analisis Titik Impas (BEP) } \\
\cline { 3 - 4 } & & BEP Unit & BEP Harga \\
\hline 1 & UKM Dodol Coklat & 8.266 & 110.155 .234 \\
\hline
\end{tabular}

Pada Tabel 2 terlihat nilai titk impas UKM dodol coklat menghasilkan nilai BEP Unit dan BEP Harga yakni nilai BEP Unit sebesar 8.266 unit dan nilai BEP Harga sebesar Rp. 110.155.234.

\section{e. Proyeksi Rugi dan Laba Usaha}

Tabel 3. Proyeksi rugi laba pada perencanaan kajian 5 tahun periode.

\begin{tabular}{|c|c|c|c|c|c|c|}
\hline \multirow{2}{*}{ No } & \multirow{2}{*}{ Nama UKM } & \multicolumn{5}{|c|}{ Proyeksi rugi laba pertahun $(\mathrm{Rp})$} \\
\hline & & Tahun 1 & Tahun 2 & Tahun 3 & Tahun 4 & Tahun 5 \\
\hline 1 & UKM Dodol Coklat & 38.713 .587 & 58.315 .587 & 76.964 .217 & 97.519 .587 & 96.566 .217 \\
\hline
\end{tabular}

f. Aliran Kas Usaha

\begin{tabular}{lrrrrr}
\hline \multicolumn{1}{c}{ Keterangan } & \multicolumn{1}{c}{ Tahun ke-1 } & \multicolumn{1}{c}{ Tahun Ke-2 } & \multicolumn{1}{c}{ Tahun Ke-3 } & \multicolumn{1}{c}{ Tahun Ke-4 } & \multicolumn{1}{c}{ Tahun Ke-5 } \\
\hline Kas Masuk & & & & & \\
Penerimaan & 257.400 .000 & 277.200 .000 & 297.000 .000 & 316.800 .000 & 316.800 .000 \\
Total & 257.400 .000 & 277.200 .000 & 297.000 .000 & 316.800 .000 & 316.800 .000 \\
$\begin{array}{l}\text { Penerimaan } \\
\text { Kas Keluar }\end{array}$ & & & & & \\
Biaya oprasional & 216.347 .683 & 216.347 .683 & 216.829 .183 & 216.347 .683 & 216.829 .183 \\
Perbaikan & & & 481.500 & & 481.500 \\
Pajak & 391.046 & 589.046 & 777.416 & 985.046 & 975.416 \\
Total & 216.738 .730 & 216.936 .730 & 218.088 .100 & 217.332 .730 & 218.286 .100 \\
Pengeluaran & 40.661 .270 & 60.263 .270 & 78.911 .900 & 99.467 .270 & 98.513 .900 \\
Sisa & 9.050 .000 & 9.050 .000 & 9.050 .000 & 9.050 .000 & 9.050 .000 \\
Saldo Kas & 40.661 .270 & 60.263 .270 & 78.911 .900 & 99.467 .270 & 98.513 .900 \\
Minimum & & & &
\end{tabular}


Proyeksi aliran kas dapat dilihat nilai positif kas proyek pada UKM dodol coklat sudah tercapai pada tahun ke-1. Hal ini menunjukan bahwa aliran kas berbanding lurus dengan payback period dan proyeksi rugi laba.

\section{g. Analisis Kelayakan Investasi}

Tabel 4. Analisis kelayakan usaha dodol coklat skala kecil

\begin{tabular}{|cccccc}
\hline \multirow{2}{*}{ No } & \multirow{2}{*}{ Nama UKM } & \multicolumn{4}{c}{ Kriteria Investasi Sebelum Perubahan } \\
\cline { 3 - 6 } & & NPV (Rp) & Net B/C & IRR & PP (Bulan) \\
\hline 1 & Dodol Coklat & 181.209 .261 & 1.34 & $192 \%$ & 12.35 \\
\hline
\end{tabular}

Pada tabel 4. dapat dilihat bahwa secara keseluruhan usaha dodol coklat yang dianalisis dalam penelitian ini secara finansial layak untuk diusahakan (menguntungkan). Hal ini dapat terlihat dari nilai bersih yang diukur dengan tingkat suku bunga yang berlaku (NPV) dan Net B/C yang menunjukan angka positif. Hasil analisis IRR menunjukkan bahwa untuk menginvestasikan modal dalam usaha dodol coklat lebih menguntungkan bila dibandingkan menyimpan modal tersebut di bank. Hal ini ditunjukan dengan nilai IRR melebihi rata-rata tingkat suku bunga yang berlaku di bank yaitu $22 \%$.

\section{h. Analisis Sensitivitas}

Analisis sensitivitas merupakan analisis yang dilakukan untuk mengetahui akibat dari perubahan faktor variabel yang mengalami fluktuasi dan dapat mengantisipasi akibat yang mungkin terjadi dari perubahan tersebut. Analisis sensitivitas didasarkan pada sensitivitas investasi perubahan nilai IRR. NPV. B/C dan PP. Berikut ini adalah perubahan tingkat sensitivitas usaha kecil dodol coklat.

Tabel 5. Nilai Kriteria Investasi Akibat Kenaikan Harga Bahan Baku Kakao

\begin{tabular}{cccccc}
\hline $\begin{array}{c}\text { Tahun } \\
\text { ke }\end{array}$ & $\begin{array}{c}\text { Persentase kenaikan harga } \\
\text { kakao }\end{array}$ & NPV (Rp) & Net B/C & IRR & PP \\
\hline 1 & $10 \%$ & 174.935 .073 & 1.33 & $183 \%$ & 12.31 \\
2 & $20 \%$ & 168.660 .885 & 1.31 & $174 \%$ & 12.26 \\
3 & $30 \%$ & 162.386 .697 & 1.29 & $165 \%$ & 12.20 \\
4 & $40 \%$ & 156.112 .510 & 1.28 & $157 \%$ & 12.13 \\
5 & $50 \%$ & 149.838 .322 & 1.26 & $148 \%$ & 12.04 \\
\hline
\end{tabular}

Dari Tabel 5. dapat dilihat bahwa kenaikan harga bahan baku kakao sampai dengan $50 \%$ masih menghasilkan nilai NPV dan Net B/C positif dan IRR berada diatas tingkat suku bunga bank $22 \%$ sehingga dapat disimpulkan bahwa usaha tersebut masih dapat dikatakan layak.

Tabel 6. Nilai Kriteria Investasi Akibat Kenaikan Harga Bahan Bakar

\begin{tabular}{cccccc}
\hline Tahun ke & $\begin{array}{c}\text { Persentase kenaikan harga } \\
\text { bahan bakar }\end{array}$ & NPV (Rp) & Net B/C & IRR & PP \\
\hline 1 & $15 \%$ & 178.699 .586 & 1.34 & $188 \%$ & 12.34 \\
2 & $30 \%$ & 176.189 .911 & 1.33 & $185 \%$ & 12.32 \\
3 & $45 \%$ & 173.680 .235 & 1.32 & $181 \%$ & 12.30 \\
4 & $60 \%$ & 171.170 .560 & 1.32 & $178 \%$ & 12.28 \\
5 & $90 \%$ & 166.151 .210 & 1.30 & $171 \%$ & 12.23 \\
\hline
\end{tabular}


Dari Tabel 6. dapat dilihat bahwa kenaikan harga bahan bakar sampai dengan $90 \%$ masih menghasilkan nilai NPV dan Net B/C positif dan IRR berada diatas tingkat suku bunga bank $22 \%$ sehingga dapat disimpulkan bahwa usaha tersebut masih dapat dikatakan layak.

\section{KEKSIMPULAN}

Hasil kriteria kelayakan usaha dodol coklat skala rumah tangga menghasilkan nilai NPV >0. IRR $>$ tingkat bunga yakni $22 \%$. Net $\mathrm{B} / \mathrm{C}>1$. $\mathrm{PP}<$ umur proyek dan sensitivitas kenaikan harga bahan baku kakao 10\% -50\% dan harga bahan bakar 15\%-90\% terhadap perubahan nilai kriteria kelayakan investasi usaha dodol coklat yakni tetap layak untuk dilanjutkan.

\section{DAFTAR PUSTAKA}

Badan Pusat Statistik. 2011. Statistik Indonesia 2011. Jakarta: BPS.

Badan Pusat Statistik. 2012. Produksi Kakao Provinsi lampung. http://Lampung.BPS.go.id. Diakses Pada 15 Desember 2013.

Direktorat Jenderal Perkebunan. 2012. Gerakan Peningkatan Produksi dan Mutu Kakao. http:/ditjenbun.deptan.go.id. Data diakses 26 Juni 2013. Ekonomi Universitas Indonesia.

Kadariah. K. dan Gray. 1999. Pengantar Evaluasi Proyek. Jakarta: Fakultas

Othman. A.. A. Ismail. N.A. Ghani. 2007. Antioxidant Capacity and Phenolic Content of Cocoa Beans. Faculty of Medicine and Health Sciences. University Putra Malaysia. 43400 UPM. Serdang. Selangor. Malaysia.Purnomo. H. 1995. Aktivitas Air dan Peranannya Dalam Pengawetan. Universitas Indonesia Press. Jakarta.

Rizki. 2011. Analisis Kelayakan Finansial Usaha Ternak Sapi Perah di Desa Purwosari Kecamatan Metro Utara Kota Metro. Skripsi.Universitas Lampung.Lampung.

Badan Pusat Statistik. 2011. Statistik Indonesia 2011. Jakarta: BPS.

Badan Pusat Statistik. 2012. Produksi Kakao Provinsi lampung. http://Lampung.BPS.go.id. Diakses Pada 15 Desember 2013.

Badan Standarisasi Nasional. 2013. Standar Nasional Mutu Dodol (SNI 01-2986-2013). BSN, Jakarta.

Direktorat Jenderal Perkebunan. 2012. Gerakan Peningkatan Produksi dan Mutu Kakaø. http:/ditjenbun.deptan.go.id. Data diakses 26 Juni 2013.

Kadariah, K. dan Gray. 1999. Pengantar Evaluasi Proyek. Jakarta: Fakultas Ekenomi Universitas Indonesia.

Othman, A., A.Ismail, N.A. Ghani. 2007. Antioxidant Capacity and Phenolic Content of Cocoa Beans. Faculty of Medicine and Health Seiences. University Putra Malaysia, 43400 UPM, Serdang, Selangor. Malaysia.Purnomo, H. 1995. Aktivitas Air dan Peranannya Dalam Pengawetan. Universitas Indonesia Press. Jakarta. 
Fibra Nurainy dkk : Analisis Finansial Dan Sensitivitas Usaha Kecil Menengah Dodol Coklat

Rizza, RA; Liang, V., Me.Mohan, M. and Harrisen, G. 2000. Encyclopedia of Foods : A Guide to Healthy Nutrition. Academic Press. London Nutr. $73: 36 \quad 40: 403 \quad 406$.

Rizki. 2011. Analisis Kelayakan Finansial Usaha Ternak Sapi Perah di Desa Purwosari Kecamatan Metro Utara Kota Metro. Skripsi.Universitas_ Lampung.Lampung.

Sjahrial, D. 2008. Manajemen Keuangan. Edisi 2.Penerbit Mitra Wacana Media. Jakarta. 